\title{
DESIGN NA ERA DA INFORMAÇÃO: O PARADIGMA AMBIENTAL E AS NOVAS CONEXÕES
}

Gabriel Esteves de Oliveira Leitão

Pontifícia Universidade Católica do Rio de Janeiro, PUC-Rio

Vera Maria Marsicano Damazio, Drạ

Pontifícia Universidade Católica do Rio de Janeiro, PUC-Rio

vdamazio@puc-rio.br

Resumo: Este artigo propõe discutir novas possibilidades que se apresentam para o design, partindo de paradigmas levantados por Alain Findeli, no artigo Rethinking Design Education for the 21st Century: Theoretical, Methodological, and Ethical Discussion, com foco nas bases materialistas da profissão e uma atual desmaterialização vivida pelo campo. O trabalho discute também a responsabilidade do papel do designer em um momento de transição de uma sociedade baseada no consumo de bens materiais para outra que consome serviços e bens intangíveis. Além disso, aborda a crise ambiental e possíveis soluções para problemas complexos viabilizadas pelo avanço das tecnologias de informação e comunicação.

Palavras-chave: design, crise ambiental, desmaterialização, sociedade em rede

Abstract: This article aims to discuss new opportunities that emerge to design, coming from paradigms appointed by Alain Findeli, on the Article Rethinking Design Education for the 21st Century: Theoretical, Methodological, and Ethical Discussion, focusing on the materialistic basis of the profession and a current dematerialization lived in the field. It also discusses the the designer's role in a moment of transition between a society based on consumption of material goods and one based in services. Furthermore, it argues about the environmental crisis and possible solutions to complex problems made possible by advances in information and communication technologies.

Keywords: design, environmental crisis, dematerialization, networked society 


\section{INTRODUÇÃO}

O mundo está mudando e com ele todas as áreas de atividade e conhecimento. Entre os aspectos que contribuiram para a atual mudança do design enquanto profissão, apontados por Alain Findeli (2001) destacam-se: 1) os efeitos da engenharia de produção e marketing no design; (2) o determinismo da razão instrumental, e papel central do fator econômico como algo exclusivo no critério de avaliação; (3) uma antropologia filosófica extremamente estreita, que considera o usuário um mero consumidor, ou, no máximo, em um ser humano enquadrado em ergonomia e psicologia cognitiva; (4) uma epistemologia do design herdada do século dezenove; (5) uma ênfase nos produtos materiais; (6) uma estética baseada em formas e qualidades; (7) um código de ética originado numa cultura de contratos e acordos de negócios; (8) uma cosmologia restrita ao mercado; (9) um senso histórico condicionado pelo conceito do progresso material e (10) um senso de tempo limitado nos ciclos da moda e das inovações tecnológicas ou obsolescência.

O autor ressalta que as preocupações ambientais devem ocupar um papel central e alerta para o risco do foco na degradação ambiental eclipsar as degradações sociais e culturais. Para Findeli, mais do que contribuir para a sustentabilidade do mundo natural, o Design deve contribuir com a construção de uma "humanidade equilibrada em um mundo equilibrado" (FINDELI, 2001).

\section{O PARADIGMA AMBIENTAL}

A incidência dos desastres naturais no mundo está aumentando. Dentre os fatores responsáveis citam-se as mudanças climáticas, intensificadas nos últimos anos; o aumento populacional e a segregação sócio-espacial (e o conseqüente aumento de favelas e bolsões de pobreza) em áreas de risco.

Relatórios elaborados anualmente para o IPCC (Painel Intergovernamental sobre Mudanças Climáticas), por centenas de cientistas de todo o mundo revelam que eventos climáticos extremos serão, em geral, mais graves e mais freqüentes nas próximas décadas.

Embora o número de céticos ainda seja grande, dados recentes indicam que a freqüência anual de desastres de grande escala praticamente triplicou desde a década de $1970^{1}$. Além disso, a concentração dos gases do efeito estufa - dióxido de carbono e metano - na atmosfera ocorreu de forma extremamente rápida nos últimos cem anos, em conseqüência de atividades humanas como a queima de combustíveis fosseis e o desflorestamento ${ }^{2}$.

Segundo Peter Doran e Maggie Zimmerman (2009), 96,2\% dos cientistas especializados em clima concordam que a temperatura média global está se elevando e $97,4 \%$ concordam que este aumento na temperatura é causado por atividades

\footnotetext{
${ }^{1}$ Fonte: Site www.inpe.br/crs/geodesastres/mudancas. Acesso em: 15 nov. 2012

${ }^{2}$ Fonte: Site

www.gpda.ufsc.br/wpcontent/uploads/2012/05/2.\%20RISCOS\%20DE\%20EVENTOS\%20METEOROLOGIC OS\%20EXTREMOS\%20DIANTE\%20DAS\%20MUDAN\%C3\%87AS\%20CLIMATICAS.pdf. Acesso em: 15 nov. 2012
} 
humanas ${ }^{3}$. Até mesmo o físico norte-americano Richard Muller (2012), considerado o maior cético das teorias do aquecimento global, admitiu que o homem está, de fato, mudando a temperatura do globo (2012). Os resultados de sua pesquisa comprovam que a temperatura da terra subiu $1,5^{\circ} \mathrm{C}$ em 250 anos, sendo que em apenas 50 anos o aumento foi de $0,9^{\circ} \mathrm{C}^{4}$.

A elevação da temperatura média da Terra tem como consequência maiores taxas de evaporação, tornando ainda mais severo o clima nas regiões áridas e desérticas, e, por outro lado, aumentando a retenção de água na atmosfera e ocasionando chuvas mais fortes e intensas. As enchentes e deslizamentos, ocasionados pelas grandes tempestades, atingem $29 \%$ das pessoas, e são responsáveis por impressionantes 73\% das mortes provocadas pelos desastres naturais (GAR 2011).

Agravando o dramático quadro da seca de um lado e inundações do outro, existem ainda os efeitos pós desastre, responsáveis por epidemias e fome, que são subestimados e não entram na contagem de atingidos diretamente pelas mudanças no clima.

Conforme apresentado pelo sociólogo francês Alain Touraine (1998, p. 43), a atual crise ambiental acontece pelo "fato de a própria sociedade industrial se pôr em perigo (self-endangerment)". Indicando o potencial de transformação das ações humanas, Touraine afirma que "nossa sociedade pode muito bem se desfazer ou ser atingida por uma catástrofe criada pelo seu próprio funcionamento". Neste sentido, propõe uma reflexão sobre o papel da sociedade para evitar o que o sociólogo Ulrich Beck denominou de "reflexividade inconsciente", ou a capacidade da sociedade se expor a riscos que podem acabar na sua destruição. (Beck apud TOURAINE, 1998, p. 43). Para o designer italiano Ézio Manzini (2008, p. 25),

O que tem que acontecer, e, na prática, já está acontecendo, é uma descontinuidade sistêmica, ou seja, uma forma de mudança em cujo final o sistema em questão - em nosso caso, o complexo sistema sociotécnico no qual as sociedades industriais estão baseadas - será diferente, estruturalmente diferente, daquilo que tivemos conhecimento até hoje.

\section{AS NOVAS CONEXÕES E AS NOVAS POSSIBILIDADES DE TRANSFORMAÇÕES}

Como observa Manuel Castells (1999, p. 67), estamos passando por uma "transformação de nossa cultura material pelos mecanismos de um novo paradigma tecnológico que se organiza em torno da tecnologia da informação" Segundo o autor, a revolução da tecnologia da informação, que vivemos no final do século XX é "um evento histórico da mesma importância da Revolução Industrial do séc. XVIII, induzindo um padrão de descontinuidade nas bases materiais da economia, sociedade e cultura" (CASTELLS, 1999, p. 68). Essa revolução foi alimentada pelas tecnologias da informação, processamento e comunicação, do mesmo modo como a eletricidade e os combustíveis fosseis alimentaram a Revolução Industrial.

\footnotetext{
${ }^{3}$ Fonte: Site

www.gpda.ufsc.br/wpcontent/uploads/2012/05/2.\%20RISCOS\%20DE\%20EVENTOS\%20METEOROLOGIC OS\%20EXTREMOS\%20DIANTE\%20DAS\%20MUDAN\%C3\%87AS\%20CLIMATICAS.pdf. Acesso em: 15 nov. 2012

${ }^{4}$ Fonte: Site www.institutocarbonobrasil.org.br/noticias2/noticia=731317. Acesso em: 15 nov. 2012
} 
Paula Pereira e Jorge Campos (2009) acrescentam que as sociedades contemporâneas organizadas em redes, vem propiciando "um cenário com um potencial de conectividade sem precedentes, particularmente propício para que organizações colaborativas, pequenas e interconectadas, possam se desenvolver a ponto de se tornarem um autêntico referencial para as novas configurações sociais...". Os autores ressaltam que, "a convergência dos fenômenos tecnológicos atuais, como as redes sociais, por exemplo, podem ser responsáveis por mudanças substanciais no rumo dos acontecimentos" (PEREIRA e CAMPOS, 2009). Um exemplo bem sucedido das possibilidades de benefícios promovidos pelos novos modelos de conexão é a comunidade de mobilização social AVAAZ (que significa voz em diversas línguas do mundo). A comunidade foi lançada em 2007 com a missão de "mobilizar pessoas de todos os países com o objetivo de construir uma ponte entre o mundo em que vivemos e o mundo que a maioria das pessoas quer ${ }^{5 "}$. Para tanto, oferece um canal para a união de forças entre indivíduos de todo o mundo para cobrar respostas das autoridades a problemas urgentes, como fome, guerras e mudanças climáticas, por exemplo. Dentre os resultados alcançados pela rede estão as doações de US\$ 2 milhões de dólares para apoiar os esforços humanitários em conseqüência do ciclone Nargis, em Mianmar; a de US\$1,3 milhões de dólares para o auxilio e recuperação do Haiti após o terremoto de 2010; além de conquistas no combate à corrupção, lutas a favor dos direitos humanos, pela paz, etc.

Sobre o potencial de transformação da aliança entre as novas tecnologias e a sociedade civil, Manzini afirma que:

“...as comunidades criativas trarão toda a riqueza das pessoas envolvidas em problemas reais e cotidianos; as redes sociais trarão oportunidades sem precedentes abertas por seus modelos organizacionais inéditos..."

(Manzini, 2008)

São muitos e crescentes os exemplos para ilustrar como as novas tecnologias vem favorecendo a cooperação entre individuos e atuação conjunta em causas diversas. Pessoas de diferentes lugares do mundo que vivem problemas semelhantes podem se comunicar, se organizar e encontrar soluções para seus problemas. Além disso, a rápida transmissão de informações permite que se acompanhe, por exemplo, a destruição causada por um tsunami do outro lado do mundo ao vivo e como se estivesse acontecendo na sua própria cidade, gerando empatia, comoção e envolvimento na resolução dos problemas gerados por tal catástrofe. Podemos dizer,que a os meios digitais de comunicação vem contribuindo para a globalização da solidariedade e da capacidade de cooperar, na medida em que aproxima tudo e todos a "um clique" de distância. As novas tecnologias, de um modo geral, estão revolucionando a nossa forma de pensar e agir.

Richard Sennet (2012, p. 20), sociólogo americano, pontua que "a capacidade de cooperar de maneiras complexas está enraizada nas etapas iniciais do desenvolvimento humano" e não desaparece na vida adulta. Sendo assim, podemos dizer que as conexões existentes em uma sociedade em rede viabilizam a cooperação entre as pessoas como nunca antes na história da humanidade, criando um terreno

\footnotetext{
${ }^{5}$ Fonte: Site www.avaaz.org/po/about. Acesso em: 21 nov. 2012
} 
extremamente promissor para a atuação de profissionais como designers, que podem criar meios ideais para mudanças desejáveis de conduta, envolvendo inúmeros atores sociais, tornando o projeto mais amplo, inclusivo e relevante, com o potencial de moldar novas realidades.

\section{UM NOVO PARADIGMA PARA O DESIGN?}

As novas tecnologias de informação e comunicação possibilitam o encontro de pessoas e a troca idéias e apresentam-se como ferramentas promissoras para a discussão e resolução de problemas complexos. A relação entre o processo do Design e a atuação de pessoas em rede promovida pelos novos meios de comunicação na busca de soluções para problemas complexos ganha forma na afirmação do filósofo Vilém Flusser de que:

"A produção industrial, inclusive o design, desenvolveu-se até se converter em uma complexa rede que se serve de informações de diversas áreas (...) por isso tornou-se necessária a atuação em grupos, em equipes compostas de elementos humanos e artificiais; desse modo, o resultado não pode ser atribuído a um único autor. O processo do design está, portanto, organizado sobre uma base extremamente cooperativa." (FLUSSER, 2007)

A designer Karine Freire também apresenta mudanças nos papéis atribuídos a designers com o passar do tempo:

Enquanto os símbolos (comunicação) e as coisas (artefatos físicos) foram centrais para o estabelecimento da profissão de designer gráfico e designer industrial no século $X X$, no século $X X I$, ganharam outro valor, na medida em que foram interpretados como parte da experiência de vida dos seres humanos, apoiando-os na performance de suas próprias ações e experiências. Esse fato provocou uma reorientação do campo para as ações (design de interação) e para as ideias (design de sistema), no âmbito dos quais os seres humanos selecionam e usam os produtos quotidianamente. (FREIRE, 2009, p. 28-29)

Freire acrescenta ainda que:

A transformação do ambiente físico, social e cultural ocorrida no final do século $X X$, proporcionada pela chamada era da informação, implicou profundas mudanças no sistema econômico, na configuração das organizações e dos relacionamentos entre elas e o ambiente, bem como nas maneiras pelas quais os indivíduos interagem. Isso proporcionou uma aproximação entre o campo do design e os serviços... (FREIRE, 2009, p. 46)

Sendo assim, meios pelo qual o design opera não precisam mais necessariamente ser objetos materiais, mas também os serviços "imateriais". Manzini (2009) entende que o design de serviços é - ou pode vir a ser - uma ferramenta poderosa para promover mudanças sustentáveis. Entendendo os serviços como produtos imateriais, não seria essa uma forma eficiente de evitar problemas gerados pelo uso abusivo de recursos naturais e problemas de descartes de bens de consumo, além de promover mudanças efetivas na vida das pessoas? Ao possibiltar a conexão entre um grande número de indivíduos, necessidades e idéias, essas redes poderiam abrigar também serviços inovadores que melhorem a qualidade de vida das pessoas e 
resolvam ou minimizem problemas complexos contemporâneos?

Segundo Findeli (2001), a desmaterialização do mundo e do design começou, principalmente, com a exposição "Les Immatériaux" em 1985, onde, segundo o autor, os produtos deixaram de ser o alvo do design. Para Findeli, a sobrevivência do design estaria ligada ao desaparecimento dos produtos no terreno ecológico, logo, ao surgimento de produtos imateriais, ou serviços.

Isso permitiu o surgimento de uma visão sistêmica sobre o projeto de serviços, com uma abordagem centrada no usuário, agora integrando produtos, processos e pontos de contato (FREIRE, 2011, p. 47). Sob essa ótica, o designer não deveria mais projetar produtos para serem possuídos pelos consumidores, mas criar serviços que estimulassem apenas o uso dos produtos. Para Manzini (2008, p. 29), é necessário mudar o centro de interesse das coisas para os resultados, por exemplo, ao invés de ter um carro, conseguir mover-se de maneira eficiente pela cidade. De acordo com Freire, o design de serviços poderia ser definido como:

$\mathrm{O}$ ato de conceber, planejar e construir, um sistema interativo, ou arquitetura de serviço, que tem o objetivo de disponibilizar recursos para apoiar as interações entre o usuário e o fornecedor (FREIRE, 2001, p. 49).

No entanto, os serviços podem, além apoiar o contato entre usuário e fornecedor, facilitar e promover o contato entre pessoas de um modo geral, servindo como meio para transformar realidades existentes em outras mais desejáveis.

Podemos resumir que as novas tecnologias de informação e comunicação apresentam-se como ferramentas promissoras para a discussão e resolução de problemas complexos, ao permitir o encontro de um número considerável de pessoas e idéias, trazendo novas ferramentas e possibilidades de atuação para profissionais como designers. Isso acontece em um momento importante, pois conforme apresentado nas páginas iniciais deste artigo, os impactos causados por fenômenos naturais ligados às mudanças no clima em comunidades vulneráveis são cada vez mais intensos e destrutivos.

\section{CONCLUSÃO}

Este artigo tende a levantar mais perguntas do que gerar respostas. As novas tecnologias de informação e comunicação geram possibilidades ainda pouco exploradas no campo do design? Essas tecnologias podem ser usadas para resolver ou minimizar alguns dos problemas enfrentados atualmente, como as mudanças climáticas e seus efeitos em comunidades vulneráveis? Essas redes podem/devem mudar a forma como os designer pensam e desenvolvem seus projetos? 0 design de serviços é uma nova fronteira para o campo? E afinal, para que fins o design é meio?

Findeli afirma que as metodologias desenvolvidas para o design de produtos materiais poderia ser transferida para o mundo dos serviços imateriais, caso sejam tomados os devidos cuidados epistemológicos. Para o autor, nosso século tem testemunhado uma aceleração no processo industrial, não tanto na manufatura de produtos mas na produção de serviços que modelam e condicionam nosso dia a dia: educação, saúde, lazer, comida, vida e morte, etc. 
Conforme lembra Findeli, a mudança epistemológica resultante de uma modificação da sociedade baseada no consumo de bens materiais para outra que consome serviços e bens intangíveis tem outra importância na responsabilidade do designer. A tarefa do designer criar um artefato não precisa mais ser tida como certa. Nestes sistemas complexos, espera-se que os designers ajam mais do que façam. Isso significa dizer que o quadro do projeto de design é ético, não tecnológico. A responsabilidade do design significa que o designer deve ter consciência de que toda vez que se engaja em um projeto de design, de alguma maneira ele recria o mundo (FINDELI, 2001).

O designer argentino Jorge Frascara (2002), explica que estamos passando por um momento de mudança e de necessidade de redefinir os objetivos do design e seus métodos de trabalho. Explorando uma noção contemporânea de design, ele sugere um mudança de foco dos objetos, materiais e processos de produção para os efeitos que eles terão na sociedade e no planeta, o contexto que eles serão usados, bem como suas conseqüências na vida das pessoas (DAMAZIO E FREIRE, 2012, p.2). Sendo assim, objetivo final é gerar um efeito, ou resultado positivo na sociedade. Tais resultados, quando ligados à resolução de problemas sociais complexos, são considerados inovações sociais. Essas inovações são movidas por mudanças de comportamento, na medida em que desafiam formas tradicionais de fazer as coisas e introduzem novas. As tecnologias de informação e comunicação contemporâneas e o desenho de serviços podem ser essa "nova forma" de fazer as coisas no design?

O ponto principal é: neste momento de transformação, os designers devem dedicar esforço e atenção com as coisas que realmente importam, como "a vida, a morte, a felicidade e o bem estar das pessoas" (FRASCARA, 1997).

\section{REFERÊNCIAS}

CAMPOS, Jorge e PEREIRA, Paula. Rede Ecológica: o design como instrumento para o processo de ressingularização do tecido social. São Paulo, SP: Anais do $2^{\circ}$ Simpósio Brasileiro de Design Sustentável. 2009.

CASTELLS, Manuel, A sociedade em rede - A era da informação: Economia, Sociedade e Cultura. São Paulo, SP : Ed. Paz e Terra, 1999.

DAMAZIO, Vera e FREIRE, Karine. Some thoughts on post-industrial society and the new roles of emocional design. Proceedings of 8th International Design and Emotion Conference London. Edited by J. Brassett, J. McDonnell \& M. Malpass. 2012.

DORAN, P. T. and M. K. ZIMMERMAN, 2009: Examining the Scientific Consensus on Climate Change, Eos Trans. AGU, 90(3), 22, doi:10.1029/2009EO030002.

FINDELI, A. (2001). Rethinking Design Education for the 21st Century: Theoretical, Methodological, And Ethical Discussion. Design Issues, 17, 5-17.

FLUSSER, Vilém. O mundo codificado, por uma filosofia do design e da comunicação. Rio de Janeiro, RJ: Ed. Cosacnaify. 2007.

FRASCARA, Jorge. Design and Social Sciences: making connections. New York: Ed. Taylor \& Francis. 2002

FRASCARA, Jorge. Diseño Gráfico para La gente. Argentina: Ediciones Infinito Buenos 
Aires. 1997.

FREIRE, K. M. Design de serviços, comunicação e inovação social: um estudo sobre serviços de atenção primária à saúde. Orientador: Vera Maria Marsicano Damazio; coorientador: Everardo Pereira Guimarães Rocha. - 2011.

GAR, 2011: Global assessment report on disaster risk reduction: Reveling risks, redefining development. United Nations International Strategy for Disaster Reduction (ISDR). Website: http://www.unisdr.org/we/inform/publications/19846.

MANZINI, Ezio. Design para a inovação social e sustentabilidade: comunidades criativas, organizações colaborativas e novas redes projetuais. Rio de Janeiro, RJ: Ed. E-papers. 2008.

SENNET, Richard. Juntos: Os Rituais, os Prazeres e a Política da Cooperação. Rio de Janeiro, RJ: Ed. Record, 2012.

SMITH, Adam. Teoria dos sentimentos morais. São Paulo, SP: Ed. Martins Fontes, 1999.

TOURAINE, Alain. Poderemos Viver Juntos? Iguais e diferentes. Petrópolis, RJ: Ed. Vozes, 1998. 